\title{
Prazosin: Preliminary Report and Comparative Studies with Other Antihypertensive Agents
}

\author{
GORDON S. STOKES, MICHAEL A. WEBER
}

\section{Summary}

In a group of 14 hypertensive patients a 10-week course of treatment with prazosin 3-7.5 $\mathrm{mg} /$ day produced a significant reduction in mean blood pressure without serious side effects. The fall in diastolic pressure exceeded the response to a placebo by $10 \mathrm{~mm} \mathbf{H g}$ or more in 9 patients. The average decrease in diastolic pressure was similar to that produced by methyldopa $750 \mathrm{mg} /$ day or propranolol $120-160 \mathrm{mg} /$ day but the fall in systolic pressure was comparatively smaller, consistent with reported experimental work showing that the drug causes vasodilatation. The hypotensive effect of prazosin $1.5-3 \mathrm{mg} /$ day combined with propranolol was significantly greater than that of propranolol alone and resulted in good control of blood pressure.

\section{Introduction}

Prazosin is a new antihypertensive drug thought to have a peripheral action involving direot relaxation of vascular smooth muscle and sympathetic blockade (Pfizer, 1970). Its chemical structure is unrelated to that of any other drug currently used for the treatment of hypentension (fig. 1).

Our aim was to conduct a short-term clinical trial of prazosin (Minipress) and to compare its antihypertensive efficacy with that of methyldopa and propranolol.

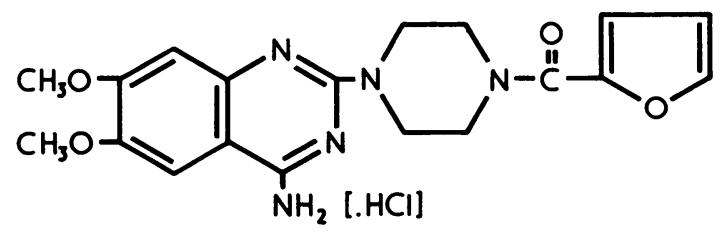

FIG. 1-Chemical structure of prazosin hydrochloride.

\section{Patients and Methods}

The informed consent of 15 hypertensive patients, seven men and eight women aged 24-51 years and weighing $54-93 \mathrm{~kg}$ (mean $73 \mathrm{~kg}$ ) was obtained for their participation in this trial. Twelve patients had had no previous treatment. Three had had previous treatment with a thiazide diuretic, which was continued throughout the trial. In all patients a detailed clinical assessment was made, including a full history, physical examination, chest $x$-ray examination, electrocardiography, intravenous pyelography, microscopical examination of urine, full blood count, and measurement of serum electrolytes, creatinine, uric acid, transaminases, alkaline phosphatase, and

\footnotetext{
Cardio-Renal Unit, Medical Research Department and Cardiovascular Clinic, Sydney Hospital, Sydney, Australia

G. S. STOKES, M.D., M.R.A.C.P., Staff Physician

M. A. WEBER, M.B., B.S., Research Fellow
}

bilirubin. One patient had minimal grade 3 hypertensive ocular fundus changes, 10 had grade 1 or 2 changes, and four had normal fundi. Serum creatinine concentration was normal in every patient.

A diagnosis of uncomplicated essential hypertension was made in 12 patients. In two other patients pyelographic evidence of analgesic nephropathy was found. The remaining patient had essential hypertension and stable angina pectoris.

After at least two baseline blood pressure readings, taken when patients were recumbent and standing, treatment was started with prazosin, 1-mg capsules by mouth, three times daily. Thereafter the patient visited the clinic at intervals of one to three weeks. At each visit blood pressure was measured to the nearest $5 \mathrm{~mm} \mathrm{Hg}$ with an Accoson sphygmomometer with a $14.5 \mathrm{~cm}$ cuff. Side effects were assessed by means of a standard questionnaire, which was filled in by the doctor after discussion with the patient.

If, after 4 weeks of treatment, the diastolic blood pressure exceeded $95 \mathrm{~mm} \mathrm{Hg}$, the dose of prazosin was increased to $2.5 \mathrm{mg}$ three times daily. If the diastolic blood pressure remained above $95 \mathrm{~mm} \mathrm{Hg}$ after seven weeks of treatment or if, at any stage, there was evidence of weight gain or ankle oedema a diuretic, cyclopenthiazide $0.5 \mathrm{mg} /$ day, was added to the treatment. After 10 weeks counterfeit placebo capsules were substituted for prazosin and were given for two to eight weeks (mean 4.3 weeks) depending upon the blood pressure response. Next came periods of treatment with methyldopa $750 \mathrm{mg} /$ day for up to 12 weeks and propranolol 120-160 mg/ day for six weeks. Finally, the propranolol was given with prazosin $1.5-3 \mathrm{mg} /$ day for six weeks and without prazosin for a further six weeks.

The first four patients in the trial were admitted for close observation and metabolic studies before prazosin therapy and during its introduction. For one week before admission they received a diet containing sodium $100 \mathrm{mEq} /$ day and this was continued in the metabolic ward. Plasma renin activity was determined using the method of Haber et al. (1969).

\section{Results}

\section{EFFECT OF PRAZOSIN ON BLOOD PRESSURE}

A 10-week trial of prazosin 3-7.5 mg/day was completed in all 15 patients. One patient, whose blood pressure fell to normal with prazosin, reacted equally well to placebo alone and was excluded from analysis. The results in the other patients were defined as "satisfactory" if standing diastolic blood pressure was reduced by $10 \mathrm{~mm} \mathrm{Hg}$ or more in excess of the effect produced by placebo or placebo plus diuretic. Such a result was achieved in nine patients while in five little or no excess effect was observed (table I). Overall the fall in blood pressure, both recumbent and standing, during treatment with prazosin was statistically significant and significantly greater than the placebo effect (table II). The response was about $50 \%$ greater in the erect than in the recumbent posture.

The time taken for the optimal effect to develop was found to be between two weeks and nine weeks, usually about four. Increasing the dosage of prazosin from $3 \mathrm{mg}$ to $7.5 \mathrm{mg}$ per day caused no appreciable improvement in blood pressure control in five patients cases $7,8,10,12,13$, table I). In the four other 
TABLE I-Serial Changes in Standing Blood Pressure (mm $\mathrm{Hg}$ ) During Treatment with Prazosin

\begin{tabular}{|c|c|c|c|c|c|c|c|c|}
\hline \multirow{3}{*}{ Case No. } & \multirow{3}{*}{$\begin{array}{c}\text { Base- } \\
\text { line } \\
\text { Pres- } \\
\text { sure }\end{array}$} & \multicolumn{5}{|c|}{ Weeks of Treatment } & \multirow{3}{*}{ Placebo } & \multirow{3}{*}{ Result } \\
\hline & & $2-4$ & $5-7$ & $8-10$ & $5-7$ & $8-10$ & & \\
\hline & & \multicolumn{3}{|c|}{$3 \mathrm{mg} / \mathrm{Day}$} & \multicolumn{2}{|c|}{$7.5 \mathrm{mg} / \mathrm{Day}$} & & \\
\hline \multirow{2}{*}{1} & 160 & 150 & 130 & 120 & & & 155 & \\
\hline & 110 & 95 & 98 & 78 & & & 100 & 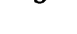 \\
\hline \multirow{2}{*}{2} & 175 & 125 & 115 & 125 & & & 145 & \\
\hline & $\overline{120}$ & $\overline{83}$ & $\overline{80}$ & $\overline{85}$ & & & $\overrightarrow{105}$ & 3 \\
\hline \multirow{2}{*}{3} & $160^{*}$ & $140^{*}$ & $123^{*}$ & $128^{*}$ & & & $175^{*}$ & $S$ \\
\hline & 115 & 103 & 83 & 88 & & & $\overline{125}$ & 0 \\
\hline \multirow{2}{*}{4} & 165 & 127 & $152^{*}$ & $145^{*}$ & & & $160^{*}$ & S \\
\hline & $\overline{125}$ & 90 & $\overline{103}$ & $\overline{105}$ & & & $\overline{120}$ & 0 \\
\hline \multirow{2}{*}{5} & 160 & 150 & $140^{*}$ & $120^{*}$ & & & $130^{*}$ & S \\
\hline & $\overline{112}$ & $\overline{108}$ & $\overline{100}$ & 90 & & & $\overline{105}$ & $\mathrm{~s}$ \\
\hline \multirow{2}{*}{6} & 158 & 148 & 140 & & & 130 & 140 & $S$ \\
\hline & 110 & 105 & 100 & & & 95 & 108 & 0 \\
\hline \multirow{2}{*}{7} & ${\underline{177^{*}}}^{-}$ & ${\underline{158^{*}}}^{-}$ & $\underline{160 *}^{*}$ & & & $152^{*}$ & $\underline{185^{*}}$ & $S$ \\
\hline & 117 & 100 & 103 & & & 100 & 120 & 6 \\
\hline \multirow{2}{*}{8} & 150 & 137 & $150^{*}$ & & & $148^{*}$ & $150^{*}$ & $\mathrm{~F}$ \\
\hline & $\overline{110}$ & 95 & $\overline{100}$ & & & 103 & 105 & $F$ \\
\hline \multirow{2}{*}{9} & 170 & 160 & & & 145 & 135 & 170 & S \\
\hline & 120 & 110 & & & $\overline{105}$ & 95 & $\overline{110}$ & 0 \\
\hline \multirow{2}{*}{10} & $\underline{170 *}^{*}$ & $\underline{165}^{*}$ & & & $155^{*}$ & $1^{151^{*}}$ & $160^{*}$ & $\mathrm{~F}$ \\
\hline & 118 & 100 & & & 95 & 101 & 110 & \\
\hline \multirow{2}{*}{11} & 210 & $177^{*}$ & & & $170^{*}$ & $160^{*}$ & $188^{*}$ & \\
\hline & $\overline{145}$ & $\overline{108}$ & & & $\overline{105}$ & $\overline{100}$ & 128 & 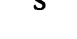 \\
\hline \multirow{2}{*}{12} & 160 & 150 & & & 148 & $140^{*}$ & $145^{*}$ & $F$ \\
\hline & 114 & 93 & & & 98 & $\overline{100}$ & $\overline{108}$ & $\boldsymbol{F}$ \\
\hline \multirow{2}{*}{13} & 160 & 140 & & & 142 & $140^{*}$ & $145^{*}$ & $F$ \\
\hline & 122 & 95 & & & 98 & 110 & 106 & 1 \\
\hline \multirow{2}{*}{14} & 190 & 167 & & & 177 & $140^{*}$ & $\underline{130}^{*}$ & $\mathbf{F}$ \\
\hline & 105 & 92 & & & 93 & 89 & 90 & \\
\hline
\end{tabular}

*Cyclopenthiazide $0.5 \mathrm{mg} /$ day given as adjunct.

$\mathrm{S}=$ Satisfactory. $\mathrm{F}=$ Failed.

TABLE II-Statistical Significance of Effects of Prazosin on Blood Pressure

\begin{tabular}{c|c|c|c|c}
\hline Posture & $\begin{array}{c}\text { Difference* } \\
\text { between Base- } \\
\text { line and } \\
\text { Treatment } \\
\text { Values }\end{array}$ & P & $\begin{array}{c}\text { Difference* } \\
\text { between Place- } \\
\text { bo and } \\
\text { Treatment } \\
\text { Values }\end{array}$ & P \\
\hline $\begin{array}{c}\text { Recumbent: } \\
\text { Systolic } \\
\text { Diastolic }\end{array}$ & 22.7 & $<0.005$ & 11.2 & $<0.05$ \\
$\begin{array}{c}\text { Standing: } \\
\text { Systolic }\end{array}$ & 15.3 & $<0.001$ & 10.1 & $<0.005$ \\
Diastolic & 21.7 & $<0.001$ & 17.4 & $<0.005$ \\
\hline
\end{tabular}

${ }^{*}$ Mean of paired differences $(\mathrm{mm} \mathbf{H g}$ ).

patients treated with $7.5 \mathrm{mg}$ per day it was impossible to dissociate improvement due to the increased dosage from that due to a possible slow onset of action of the drug or introduction of diuretic treatment.

In four patients who were treated initially in a metabolic ward no significant changes in blood pressure, pulse rate, or body weight were produced by prazosin $3 \mathrm{mg} /$ day during a period of observation of two or three days. Sodium excretion fell slightly. There was no significant short-term effect on plasma renin activity (mean baseline value ( \pm S.E.) $8.5 \pm$ $1.6 \mathrm{ng}$, mean treatment value $7.7 \pm 1.4 \mathrm{ng}$, and mean normal value $5 \cdot 2 \pm 1.2 \mathrm{ng} / \mathrm{ml} / \mathrm{hr}$.).

\section{SIDE EFFECTS OF PRAZOSIN}

Side effects encountered during the trial of prazosin, with or without a diuretic, were dizziness in eight patients, lassitude in seven, dry mouth in five, headaches in four, nausea in three, ankle swelling or weight increase in three, diarrhoea in two, nasal stuffiness in two, chest pain in two, irritability in two, and depression in one. Though they were included in the questionnaire the following symptoms were not found: hot or cold sweats, change in urine volume, palpitations, impotence. The side effects were in general evanescent and patients mentioned them only on specific questioning. They did not cause suspension of the treatment in any case and led to a reduction of dosage in three patients only, all of whom were receiving propranolol at the same time (see below). In 10 patients the blood count and serum levels of electrolytes, creatinine, uric acid, transaminases, alkaline phosphatase, and bilirubin determined after four to 10 weeks of treatment showed no significant changes from their baseline values.

\section{COMPARISON WITH METHYLDOPA AND PROPRANOLOL}

We found prazosin, methyldopa, and propranolol equally effective in reducing diastolic pressure (table III). The average fall in systolic pressure produced by prazosin, however, was less than that produced by methyldopa or propranolol, panticularly in the recumbent posture. To determine for each drug the number of patients who responded satisfactorily the blood pressure readings in the recumbent and erect postures were averaged, and those whose mean blood pressure (diastolic pressure plus one third of pulse pressure) was reduced to less than $110 \mathrm{~mm}$ $\mathrm{Hg}$ or fell by more than $15 \mathrm{~mm} \mathrm{Hg}$ from the placebo level were classified as responders. By these criteria two patients (cases 12 and 13) failed to respond to any of the drugs used, and three did not respond to prazosin but responded to methyldopa and propranolol. Of the nine prazosin-responders one (case 9) did not respond either to methyldopa or to propranolol. Only five patients responded to all three drugs and in two of these methyldopa had to be withdrawn within one week because of severe side effects (diarrhoea in one patient, lassitude in the other).

TABLE III-Comparison of Effects of Treatment with Prazosin, Methyldopa, and Propranolol on Blood Pressure

\begin{tabular}{|c|c|c|c|c|c|}
\hline \multirow{2}{*}{ Medication* } & \multirow{2}{*}{$\begin{array}{c}\text { Dose } \\
(\mathrm{mg} / 24 \mathrm{hr})\end{array}$} & \multirow{2}{*}{\begin{tabular}{|c|} 
Mean \\
Duration of \\
Treatment \\
(Weeks)
\end{tabular}} & \multicolumn{2}{|c|}{$\begin{array}{c}\text { Blood Pressuret } \\
\text { (mm Hg) }\end{array}$} & \multirow{2}{*}{$\begin{array}{l}\text { No. of } \\
\text { Respond- } \\
\text { ents } \ddagger\end{array}$} \\
\hline & & & Recumbent & Standing & \\
\hline Placebo & - & $4.3\}$ & $\frac{162}{108}$ & $\frac{156}{110}$ & - \\
\hline Prazosin .. & $3-7 \cdot 5$ & $9 \cdot 6$ & $\frac{150}{98}$ & $\frac{138}{96}$ & 9 \\
\hline Methyldopa & 750 & $5 \cdot 2$ & $\frac{139}{94}$ & $\frac{136}{96}$ & 9 \\
\hline Propranolol & $120-160$ & 4.5 & $\frac{139}{96}$ & $\frac{133}{96}$ & 10 \\
\hline
\end{tabular}

* Ten patients also received cyclopenthiazide $0.5 \mathrm{mg} /$ day during all four phases. tAverages of optimal readings.
tOut of 14 potients. See text for criteria of response.

\section{PRAZOSIN AND PROPRANOLOL IN COMBINATION}

After the initial course of treatment with propranolol for three weeks the dosage in five patients with diastolic blood pressure below $100 \mathrm{~mm} \mathrm{Hg}$ (recumbent) was reduced from 160 to 120 $\mathrm{mg}$ per day, and the drug was discontinued in one patient because of asthma. After another three weeks of treatment with propranolol two patients whose blood pressure remained normal were discharged from the trial while the remainder with recumbent diastolic levels between 85 and $105 \mathrm{~mm} \mathrm{Hg}$, were given prazosin as adjunctive treatment for six weeks. The initial dose of prazosin was $3 \mathrm{mg} /$ day; in three patients 
who complained of dizziness this was reduced after one to three weeks to $1.5 \mathrm{mg} /$ day. The results of the combined therapy in 11 patients are shown in fig. 2 . The average blood pressure fell from 149/100 (recumbent) and 145/100 (standing) to levels of $136 / 88$ and $132 / 87$ respectively, which were lower than those produced by any of the drugs used singly. Suspension of prazosin therapy during continued treatment with propranolol resulted in a rise in blood pressure.

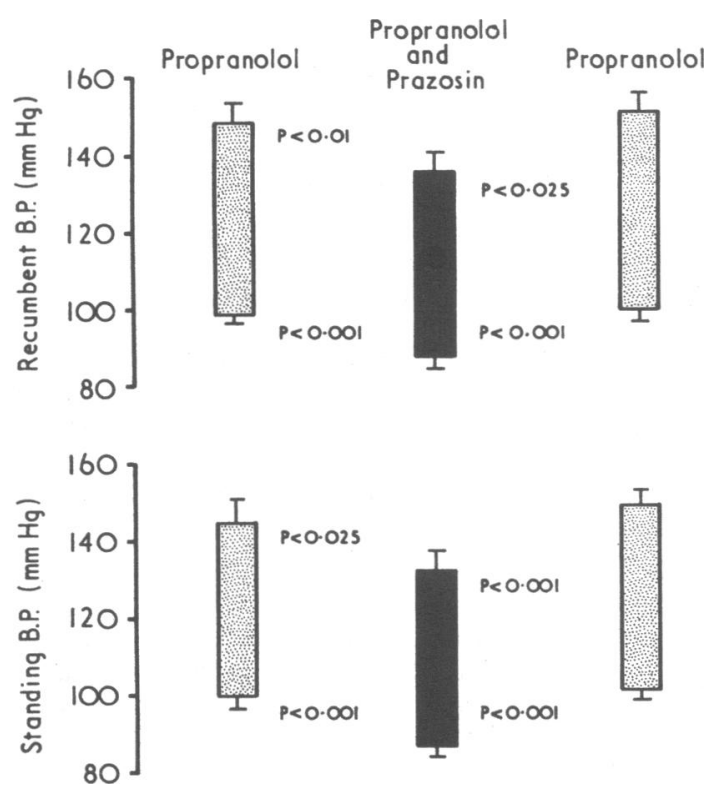

FIG. 2-Serial comparison of effects of propranolol and combination of propranolol and prazosin in 11 patients, six of whom were also receiving propranolol and prazosin in 11 patients, six of whom were also receiving
diuretics. Each regimen was six weeks. Dose: propranolol $120-160 \mathrm{mg} / \mathrm{day}$, prazosin 1.5-3 mg/day.

\section{Discussion}

This trial confirmed that prazosin $3-7.5 \mathrm{mg} /$ day has a significant antihypentensive action. When used as the sole agent in therapy it produced an adequate therapeutic response in about the same proportion of patients as conventional doses of methyldopa or propranolol, without serious side effects. Its effect on systolic blood pressure, however, was less than that of the other two agents and had a greater orthostatic component. This is consistent with experimental findings (Pfizer, 1970) which show that the primary action of the drug is to lower peripheral vascular resistance and indicate that, as with other vasodilator drugs, such as hydrallazine, diazoxide, or minoxidil, there is accelerated dissipation of the cardiac stroke volume into dilated peripheral vascular beds. Though symptomatic tachycardia and other clinical features of a high output state resulting from vasodilatation were not detected in this study prazosin manifested a potentially useful synergism with propranolol (a blocker of cardiac beta-adrenergic receptors) similar to that shown for other beta-blockers and vasodilator drug combinations (Sannerstedt et al., 1971; Zacest et al., 1972; Gottlieb et al., 1972).

Clearly it is advantageous to evaluate the antihypertensive potency of a drug by comparing its effect to that of a counterfeit placebo, particularly if the patient has not been treated before. When the placebo phase comes after treatment with an active compound which has a protracted action, however, it is possible that potency may be underestimated. Such a possibility existed in this study, which was planned without knowledge of the time taken for the effect of prazosin to disappear. Indeed, it seems from our observations that the hypotensive effect of the drug may persist for a variable period up to one month. Thus in future work it would be advisable to assess the placebo response before giving active medication and allow long washout periods in crossover studies.

Our preliminary findings indicate that prazosin warrants a longer trial, preferably incorporating a double-blind crossover design which would allow comparison with established antihypertensive agents in regand to efficacy, patient preference, and long-term side effects. Initial impressions were formed that the drug may be suitable as single-agent therapy in mild to moderate hypertension and may constitute a useful alternative to hydrallazine in combined beta-blocker and vasodilator treatment of severe hypentension.

We thank Dr. G. E. Bauer for reviewing the manuscript and Dr. B. W. Gunner of Pfizer (Australia) for supplies of prazosin.

\section{References}

Gottlieb, T. B., Katz, F. H., and Chidsey, C. A. (1972). Circulation, 45, 571. Haber, E., Koerner, T., Page, L. B., Kliman, B., and Purnode, A. (1969). Fournal of Clinical Endocrinology, 29, 1349.

Pfizer Investigator's Brochure (1970). Prazosin. Therapeutics Research Division, Pfizer Ltd., Kent.

Sannerstedt, R., Stenberg, J., Johnsson, G., and Werko, L. (1971). American fournal of Cardiology, 28, 316.

Zacest, R., Gilmore, E., and Koch-Weser, J. (1972). New England fournal of Medicine, 286, 617. 